Research Article

\title{
Effect of Colluvial Soil Slope Fracture's Anisotropy Characteristics on Rainwater Infiltration Process
}

\author{
Ling Zeng, ${ }^{1,2}$ Jie Liu, ${ }^{3}$ Jun-hui Zhang $\mathbb{D}^{3,}{ }^{3,4}$ Han-bing Bian, ${ }^{2}$ and Wei-hua $\mathrm{Lu}^{5}$ \\ ${ }^{1}$ Engineering Laboratory of Spatial Information Technology of Highway Geological Disaster Early Warning in Hunan Province, \\ Changsha University of Science \& Technology, Changsha 410114, China \\ ${ }^{2}$ School of Civil Engineering, Changsha University of Science \& Technology, Changsha 410114, China \\ ${ }^{3}$ School of Traffic and Transportation Engineering, Changsha University of Science \& Technology, Changsha 410114, China \\ ${ }^{4}$ National Engineering Laboratory of Highway Maintenance Technology, Changsha University of Science \& Technology, \\ Changsha 410114, China \\ ${ }^{5}$ School of Civil Engineering, Nanjing Forestry University, Nanjing 210037, China
}

Correspondence should be addressed to Jun-hui Zhang; zjhseu@csust.edu.cn

Received 26 June 2018; Accepted 10 September 2018; Published 17 October 2018

Academic Editor: Annan Zhou

Copyright (c) 2018 Ling Zeng et al. This is an open access article distributed under the Creative Commons Attribution License, which permits unrestricted use, distribution, and reproduction in any medium, provided the original work is properly cited.

\begin{abstract}
The SEEP/W module of finite element software GEO-slope is used to analyze the effects of fracture depth, permeability coefficient ratio, fracture angle, and fracture number on the rainwater infiltration process. Moreover, the effect of fracture seepage anisotropy on slope stability is discussed combining with unsaturated seepage theory. The results show that the pore water pressure in the fracture increases rapidly with the rainfall until it changes from negative pressure to positive pressure. The greater the fracture depth is, the greater the pore water pressure in the fracture is, and the greater the infiltration depth at the time of rainfall stopping is. When the permeability coefficient is greater than the rainfall intensity, the permeability coefficient ratio has a great influence on the infiltration process of rainwater. The smaller the fracture angle is, the greater the maximum pore water pressure is in the fracture depth range, and the greater the depth of the positive pore water pressure is. However, with the increase of fracture angle, the infiltration depth decreases, and the range of the surface saturation area of slope increases obviously. With the increase of fracture density, the saturated positive pressure region is connected to each other in the slope. The influence range and the degree of the rainwater on the seepage field are larger and larger. There is a power relation between the saturation area and the fracture number, and also the concentration distribution of long fractures directly forms the large-connected saturated zone and raises groundwater. The range of the saturated zone and variation law of the pore water pressure under fracture seepage are obtained, which provide a reference for the parameter partition assignment of slope stability analysis under fracture seepage.
\end{abstract}

\section{Introduction}

Colluvial soil slope whose soil layer thickness is within $7 \mathrm{~m}$ is widely distributed in the southern part of China [1]. Under the influence of rainfall, it can easily bring shallow landslide or debris flow which is the main geological hazard in southern China. A large number of engineering practices and tests have proved that the strength of slope soil has the characteristics of deterioration with increase of water content [2]. Therefore, mastering the occurrence state of rainwater in slope soil becomes the precondition for studying the stability of slope. Because the slope soil has the characteristics of low strength and strong evaporation, the peristalsis and uneven evaporation of the upper and lower layers occur after rainfall infiltration in the diluvial layer, thus causing a clear fracture. In addition, the fracture's permeability is obviously different from the surrounding soil, which induces water to infiltrate into the slope soil more quickly and expand the infiltration range. In particular, when the permeability of the undisturbed slope soil is low, the infiltrated water may change the whole seepage field of the slope above the bedrock. Therefore, the process of rainwater anisotropic infiltration induced by fractures should be analyzed in the design of drainage 
measures for colluvial soil slope. The anisotropic seepage is mainly caused by the following aspects: (1) fracture depth, (2) ratio of the permeability coefficient along the fracture direction to vertical fracture direction (permeability ratio $\mu$ ), (3) angle of fracture distribution $(\theta)$, and (4) fracture density.

At present, scholars worldwide have conducted a significant amount of research on fracture seepage. Ju et al. [3] and Qian et al. [4] studied the seepage properties of fractured rocks under different confining pressures. Chen et al. [5] and Huang et al. [6] studied the numerical calculation method of the discrete fracture model for twodimensional seepage in fractured rock. Yang et al. [7] and Chai and $\mathrm{Xu}$ [8] studied the composite element model of rock fracture seepage coupling with normal stress. Su et al. [9] and Zeng et al. [10] have carried out a rough single fracture percolation-dissolution coupling model controlled by the surface reaction and diffusion migration. Ju et al. analyzed the variation of seepage properties with fracture roughness and the influence of the rough structure on seepage mechanism through laboratory tests. In addition, the fractal model of relationship between water flow resistance and fracture roughness was obtained [3]. Liu et al. used the DFN-GEN program to generate the fracture-rock calculation model, studied the hydraulic characteristics of the fractured rock mass, and discussed the influence law of stress on the equivalent permeability coefficient of the fractured rock mass [11]. Chen and Song carried out a numerical calculation method for the discrete fracture network model for flow and heat transfer in two-dimensional fractured rocks. The model is used to simulate a randomly generated fracture network to study the characteristics of flow and heat transfer in fractured rock [12]. Leung and Zimmerman studied the fluid flow in a random two-dimensional fracture network and established a macroscopic effective hydraulic conductivity estimation method based on the fracture network parameters [13]. Xue and Chen established a composite element model considering the coupling of rock fracture seepage and normal stress. The analysis shows that the normal stress causes the seepage uneven penetration of the fractured rocks; that is, the osmotic gradient, the uplift pressure, and seepage velocity of the local area increase significantly [14]. Chen et al. discussed the seepage properties of the joint surface and derived the normal and tangential stiffness coefficient formulas of the joint plane and the equivalent permeability coefficient formula of the joint system [15]. Huo et al. established a rough singlefracture seepage-dissolution coupling model controlled by the surface reaction and diffusion migration. The results show that the distribution of aperture, flow velocity, and concentration of $\mathrm{Ca}^{2+}$ appeared as inhomogeneous wormholes. The flow through the fracture increased during the whole period of simulation, and the factor controlling the chemical reaction varied during the dissolution [16]. Su et al. believe that the overall permeability of the fracture increases slowly at the initial moment. As the aperture increases and penetrates, the dissolution rate will gradually increase, which is an accelerated process [9].
Song et al. studied the influence of fluid-solid coupling on shale mechanics and seepage laws. The shale seepage tests under different saturations show that, under fluid-solid coupling conditions, the higher the saturation, the higher the propagation and the seepage ability of microcracks under pressure [17]. Huang et al. carried out numerical analysis on the hydrothermal coupling model of lowtemperature fractured rocks. It is believed that both the fracture width and delivery head of fracture water affect completed freezing time. The completed freezing time increases with the increase of fracture width and delivery head of fracture water [6]. Zeng et al. studied the seepage law considering the formation dip angle, established the modified radial flow formula of the inclination angle, and obtained the formation pressure distribution and the production formula of the inclined formation by the plane radial seepage theory [18].

From the above studies, we can see that the existing researches mainly focus on the fracture seepage test method, numerical calculation theory, and the establishment of the constitutive model, and the research object is mostly rock fissure seepage. However, the research on soil slope fracture seepage is seldom carried out. In the last two years, the frequency of soil slope instability caused by rainfall was increasing. Therefore, the fracture causing the change of the seepage field of soil slope and leading to slope instability phenomenon ultimately cannot be ignored. This paper intends to study the influence of slope fracture anisotropy on the rainwater infiltration process in colluvial soil slope. What's more, the occurrence characteristics of rainwater under the influence of fracture anisotropy are obtained to provide a reference for slope stability analysis and design of drainage measures when fractures exist.

\section{Numerical Realization of Fracture Anisotropy}

In this paper, the SEEP/W module of finite element software GEO-slope is used to calculate the seepage process of rainwater [19]. The fracture depth, fracture angle, permeability coefficient ratio, and fracture density are simulated by the following methods [20-22]: (1) a solid element is established equivalent to a fracture in the model, and a fracture is defined as another material different from the colluvial soil; (2) to simulate the distribution of fractures by changing the length, angle, and spacing of the established fracture solid element; (3) the anisotropy of the fracture unit is simulated by defining the ratio $(\mu)$ of the permeability coefficient $\left(k^{\prime}{ }_{y}\right)$ along the direction of fracture and the permeability coefficient $\left(k_{x}^{\prime}\right)$ in the direction of vertical fracture. The angle of fractures distribution $(\theta)$ should also be taken into account here. The schematic diagram is shown in Figure 1.

In Figure 1, the fracture angle $(\theta)$, the fracture permeability coefficient $\left(k_{x}^{\prime}\right.$ and $\left.k_{y}^{\prime}\right)$, and the actual set fracture permeability coefficient $\left(k_{x}\right.$ and $k_{y}$ ) satisfy the following formula: 


$$
\begin{aligned}
\left(\begin{array}{l}
k_{x} \\
k_{y}
\end{array}\right) & =\left[\begin{array}{cc}
\cos \theta & \sin \theta \\
-\sin \theta & \cos \theta
\end{array}\right]\left(\begin{array}{l}
k_{x}^{\prime} \\
k_{y}^{\prime}
\end{array}\right), \quad\left(0 \leq \theta \leq 90^{\circ}\right), \\
\left(\begin{array}{l}
k_{x} \\
k_{y}
\end{array}\right) & =\left[\begin{array}{cc}
\cos \theta & \sin \theta \\
\sin \theta & \cos \theta
\end{array}\right]\left(\begin{array}{l}
k_{x}^{\prime} \\
k_{y}^{\prime}
\end{array}\right), \quad\left(\theta=90^{\circ}\right),
\end{aligned}
$$

where $\theta$ is the angle between the crack and the vertical direction, $k_{x}^{\prime}$ and $k_{y}^{\prime}$ are the permeability coefficients in the direction of vertical fracture and permeability coefficient along the direction of fracture, respectively, and $k_{x}$ and $k_{y}$ are the permeability coefficients along the $X$ and $Y$ directions in the global coordinate system, respectively.

\section{Numerical Model and Calculation Scheme}

3.1. Numerical Model and Boundary Conditions. A simple slope with a height of $20 \mathrm{~m}$ and an angle of $30^{\circ}$ is used in the calculation. The fracture is considered within a depth of seven meters on the surface of the slope. The fracture is designed at the middle and top of the slope. The length of fracture is $1 \mathrm{~m}, 3 \mathrm{~m}$, and $5 \mathrm{~m}$, and the angle of fracture is $0^{\circ}$, $30^{\circ}$, and $60^{\circ}$. As shown in Figure 2, the influence of the number of fractures on the seepage process is considered according to the uniform distribution of fractures in the middle and top of the slope. The numbers of fracture are 1, 2, 3,4 , and 5. In the calculation of rainfall infiltration, when the rainfall intensity is less than the saturation permeability coefficient of slope surface soil, the slope surface adopts the unit flow boundary, which is controlled by the rainfall intensity. When the rainfall intensity is greater than the permeability coefficient of slope surface soil, the slope surface is set as the head boundary.

The calculation of saturated-unsaturated seepage under rainfall condition requires an initial condition, and the infiltration of rainwater is transient seepage based on the initial condition. In the natural state, the area above the groundwater level is generally unsaturated. According to the Van Genuchten (VG) model, the natural state determines the distribution of the initial matrix suction field in the slope. However, the permeability coefficient of the unsaturated region is much smaller than that of the saturated permeability coefficient because of the existence of matrix suction. The continuous infiltration of rainwater in the slope is controlled by the permeability coefficient of the unsaturated region. Therefore, the accurate determination of the initial state is the key to simulate the rainwater infiltration process. At present, there are two representative methods for the simulation of the unsaturated region in the initial state [23]: (1) the above area of the groundwater level shall be linearly assigned according to the hydrostatic pressure, which will result in a large difference in the negative pore water pressure at different positions of the slope surface, and (2) the pore water pressure below the groundwater is calculated according to hydrostatic pressure. The pore water pressure on the underground water level is $0 \mathrm{kPa}$. The pore water pressure in the area above the underground water level is fitted by using the VG model. However, the negative pore water pressure on the slope in contact with the atmosphere should be the same.

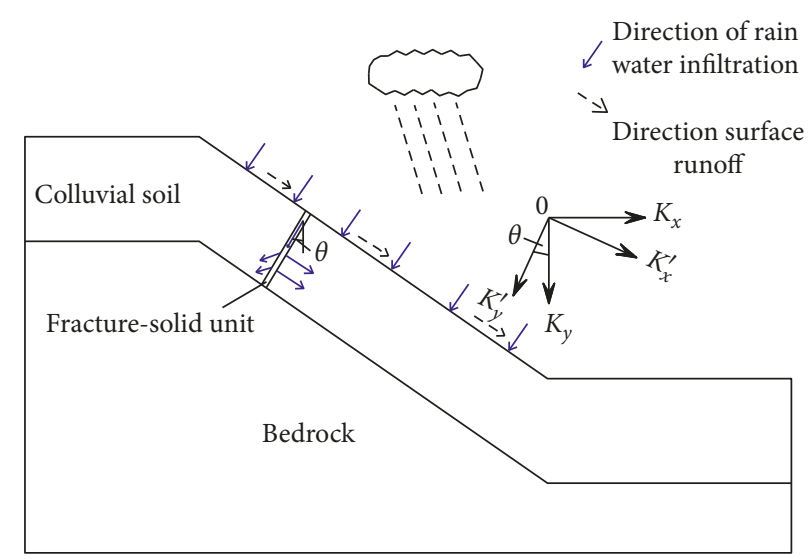

FIgURE 1: Fracture permeability coefficient and global coordinate system conversion.

As far as the literature is concerned, most scholars use the first method to simulate the initial seepage field. In fact, since the surface of slope is in contact with the atmosphere, the drought-wet degree of the slope surface is close, and the negative pore water pressure is basically the same. Therefore, the second method is used to simulate the initial seepage field of slope, as shown in Figure 3.

3.2. Calculation Parameters and Schemes. The actual project supported in this paper is the slope of K107+670 of the Rucheng-Chenzhou expressway in Hunan Province, so the parameters used in the calculation are derived from the test of undisturbed soil [24]. To obtain the permeability of weakly weathered limestone, the borehole water pressure test was carried out on the rock. According to the test results, $k_{x}=k_{y}=1.0 \times 10^{-9} \mathrm{~m} / \mathrm{s}$. The saturated permeability coefficient of homogeneous (gravel) silty clay was obtained by the laboratory test, and $k_{x}=1.0 \times 10^{-7} \mathrm{~m} / \mathrm{s}$, and $k_{y}=0.83 \times 10^{-7} \mathrm{~m} / \mathrm{s}$. The saturated water content is measured by the laboratory test of the original sample. The saturated water content of silty clay is 0.35 , and that of weakly weathered limestone is 0.05 . The residual water content $\left(w_{\mathrm{r}}\right)$ of silty clay which is acquired by the laboratory test is 0.02 .

The permeability coefficient in the direction of vertical fracture is $k_{x}^{\prime}=2.83 \times 10^{-2} \mathrm{~m} / \mathrm{s}$. The permeability coefficients along the direction of fracture are $k_{y}^{\prime}=1 k_{x}^{\prime}, 10 k_{x}^{\prime}, 100 k_{x}^{\prime}$, and $1000 k_{x}^{\prime}$, respectively, and $\mu$ are $1,10,100$, and 1000 [25]. Then, $k_{x}$ and $k_{y}$ in the global coordinate system with different permeability coefficient ratios $(\mu)$ and fracture angles $(\theta)$ are calculated according to Equations (1) and (2). The results are shown in Figure 4.

To simulate the most unfavorable rainfall conditions, the rainfall intensity value was calculated by using the maximum rainfall of 7 days in the last 20 years in the Rucheng-Chenzhou area, Hunan Province. The rainfall is $585 \mathrm{~mm}$ $\left(9.67 \times 10^{-7} \mathrm{~m} / \mathrm{s}\right)$ [26]. To consider the influence of fracture length, fracture angle, fracture permeability coefficient ratio, and fracture density on the rainwater seepage process, the designed calculation scheme is shown in Table 1. 


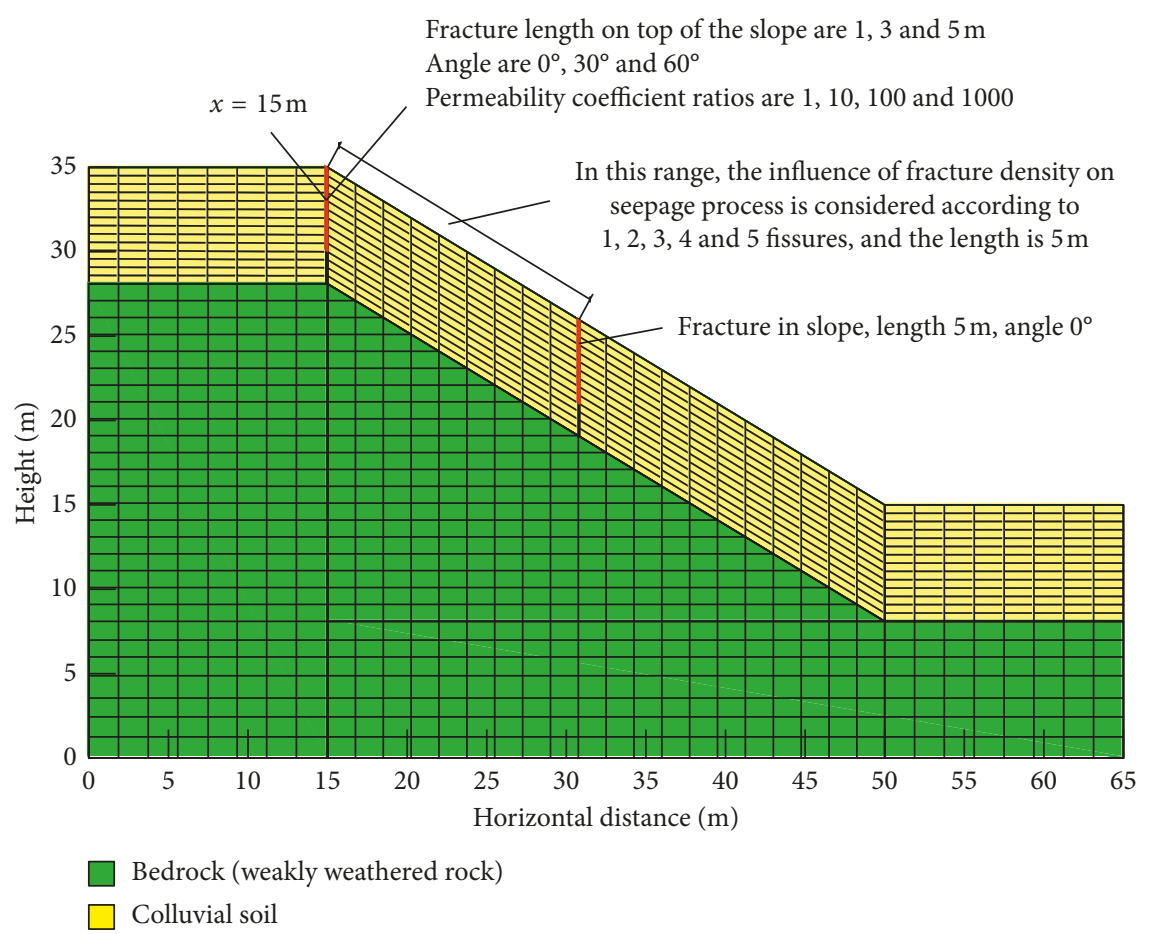

FIgURE 2: Numerical calculation model.

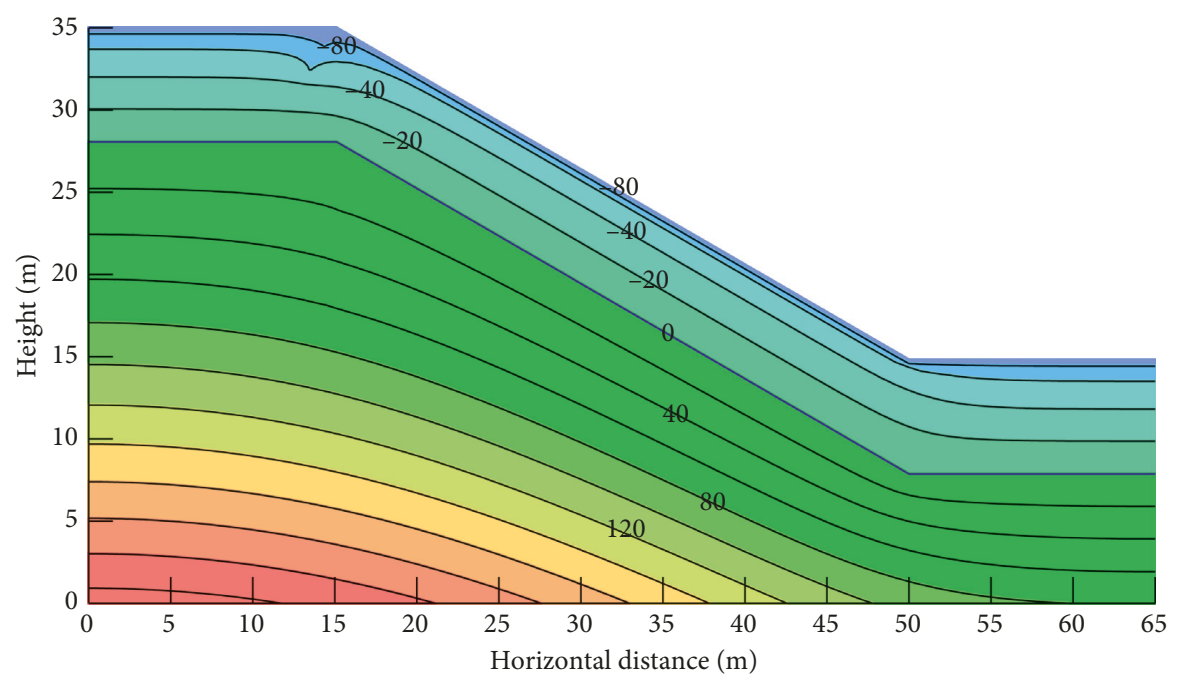

Figure 3: Initial pore water pressure distribution in slope (unit: $\mathrm{kPa}$ ).

\section{Results and Discussion}

\subsection{Influence of Fracture Anisotropy Degree on the Rainwater Infiltration Process}

4.1.1. Influence of Fracture Depth. Figure 5 shows the distribution of pore water pressure of different fracture depths along the section $(x=15 \mathrm{~m})$ at 1 and 7 days of continuous rainfall. It can be seen that the pore water pressure in the fracture increases rapidly with the rainfall until it changes from negative pressure to positive pressure. When fracture depth is $1 \mathrm{~m}$ and the duration of rainfall is $1 \mathrm{~d}$, the maximum pore water pressure in the fracture is $9.69 \mathrm{kPa}$, and the infiltration depth of rainwater along the bottom of the fracture is $0.5 \mathrm{~m}$. However, the maximum pore water pressure in the fracture is $9.70 \mathrm{kPa}$, and the infiltration depth of rainwater along the bottom of the fracture is $1.5 \mathrm{~m}$ when rainfall falls for 7 days. For $3 \mathrm{~m}$ fracture and $5 \mathrm{~m}$ fracture, the variation of pore water pressure is similar to that of $1 \mathrm{~m}$ fracture. Both show that pore water pressure of 


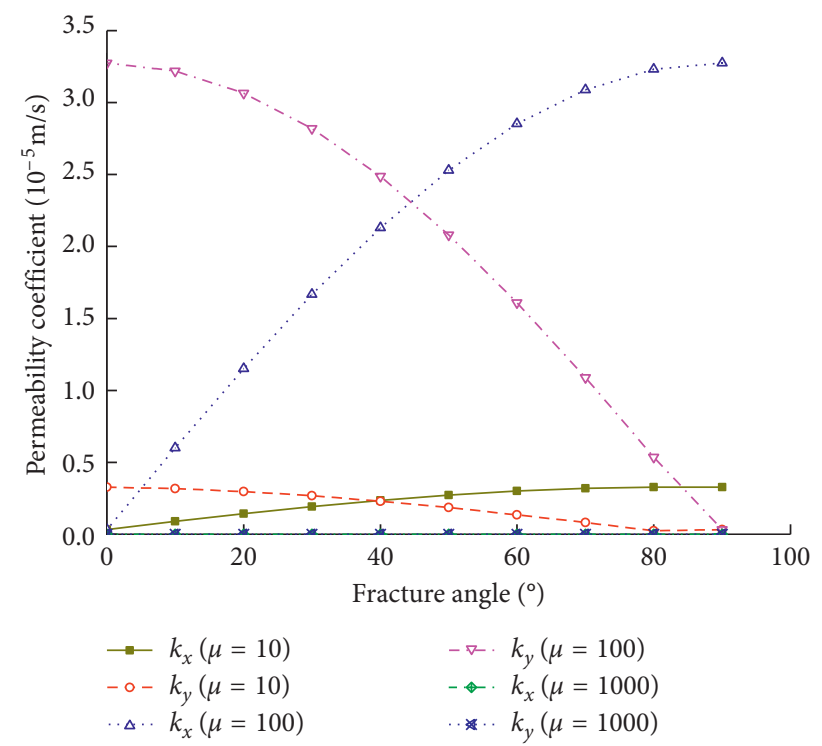

FIgURE 4: Fracture permeability coefficient in the global coordinate system.

TABLE 1: Schemes for numerical analysis.

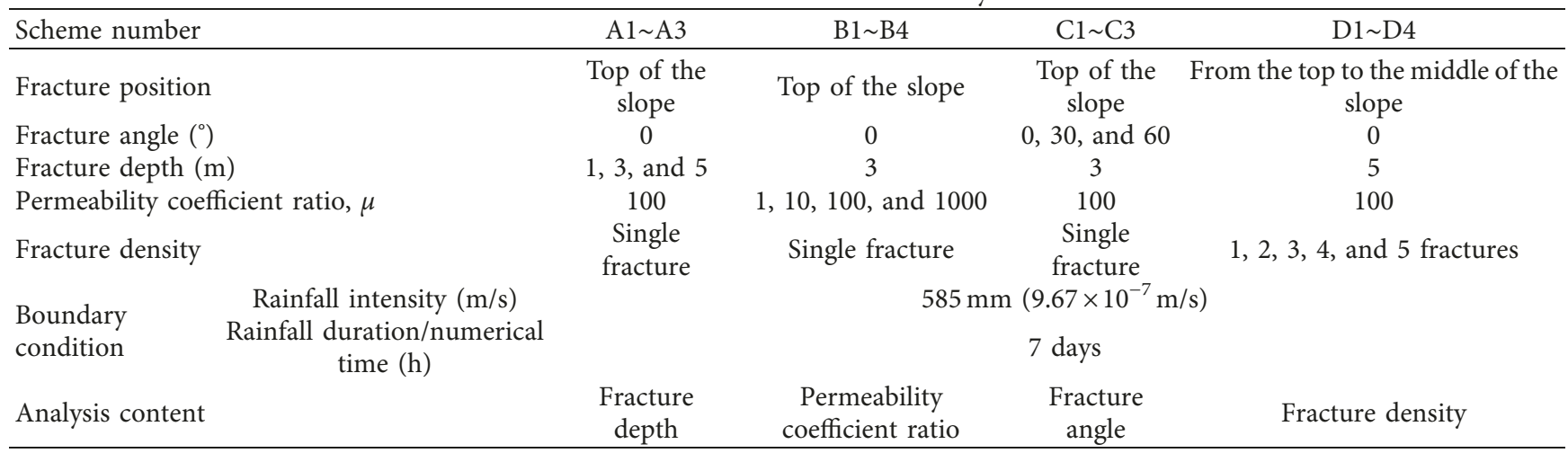

the fracture section is almost equal when rainfall is $1 \mathrm{~d}$ and $7 \mathrm{~d}$, respectively. The infiltration depth at 7 days of rainfall is obviously greater than that at 1 day, which is $2.0 \mathrm{~m}$ and $1.7 \mathrm{~m}$, respectively. The infiltration depths are greater than that of $1 \mathrm{~m}$ fracture. The results show that, after 1 day of rainfall, the fracture is almost filled with the infiltration rainwater. However, the rainwater infiltration depth is related to rainfall duration, soil permeability coefficient, and seepage boundary condition.

By analyzing the reason, because of the large permeability coefficient of the fracture, the infiltration rainwater on the slope will enter into the fracture quickly. However, because of the small permeability coefficient of soil, the rainwater in the fracture is not easy to seep out the slope soil. Rainwater will converge inside the fracture until the fracture is completely filled with rainwater. The pressure head is almost the same as the fracture depth in the fracture. When the fissure is filled with rainwater, the infiltration of fracture rainwater into the slope will be changed into pressure permeability. Therefore, the greater the fracture depth, the greater the pore water pressure in the fracture, and the greater the infiltration depth at the time of rainfall stopping.
Figure 6 shows the distribution of the saturation line around fractures at different fracture depths (7 days of rainfall). The area around the fracture is saturated after seven days of rainfall. The size of the saturated region is positively correlated with the depth of the fracture. The continuous saturation zone is not formed in the slope except the fracture. In particular, when the fracture depth is $5 \mathrm{~m}$, the saturation line down the fracture has merged with the underground water line. The saturated area increases rapidly and eventually leads to the rise of the groundwater level, which affects the seepage field of the slope to a greater extent. In conclusion, under the same conditions, the fracture depth determines the size of the saturated area around the fracture. The formation of the rapid seepage path is the direct cause of the rise of the groundwater level in the fractured slope.

4.1.2. Influence of Fracture Permeability Coefficient Ratio. Figure 7 shows the distribution curves of pore water pressure with buried depth of fracture at different fracture permeability ratios. As shown in Figure 7, after 7 days of rainfall, the pore water pressure of each scheme fracture section 


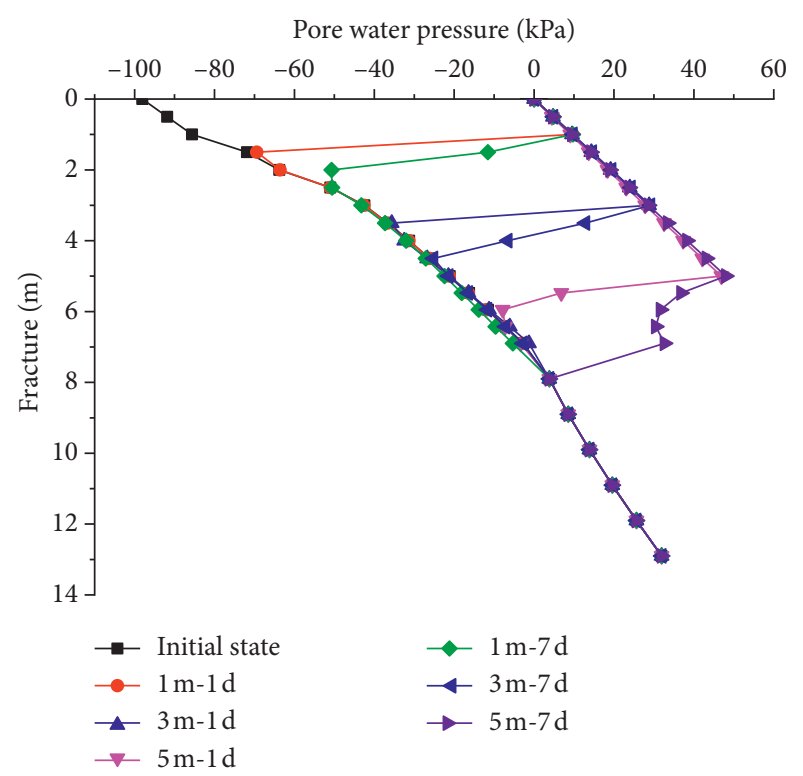

FIGURE 5: Distribution curves of pore water pressure with depth in different fracture depths $(x=15 \mathrm{~m})$.

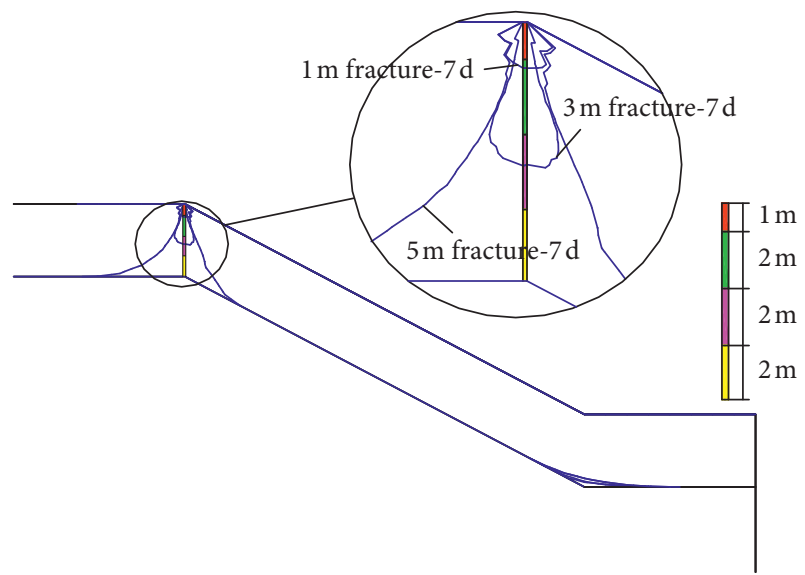

Figure 6: Distribution of the infiltration line around the fracture in different fracture depth (7 days of rain).

increases to a certain extent. When $\mu=1$, the pore water pressure decreases gradually with the increase of buried depth in the fracture range, and it is always in a negative pressure. When $\mu \geq 10$, the pore water pressure increases gradually with the increase of buried depth in the fracture range. Their pore water pressure distribution law is basically consistent, and the numerical difference is small. Figure 8 shows the distribution curve of the fracture permeability coefficient with buried depth when rainfall stops. When $\mu \geq 10$, the permeability coefficient is obviously larger than that of the initial state and $\mu=1$.

Combined with the analysis of Figures 7 and 8 , it is not difficult to find the reasons for the above phenomenon. When $\mu=1$, the unsaturated state is always maintained in the fracture range. The maximum permeability coefficient in the fracture range is $1.51 \times 10^{-7} \mathrm{~m} / \mathrm{s}$, which is less than $9.67 \times 10^{-7} \mathrm{~m} / \mathrm{s}$ of rainfall intensity. Therefore, the infiltration

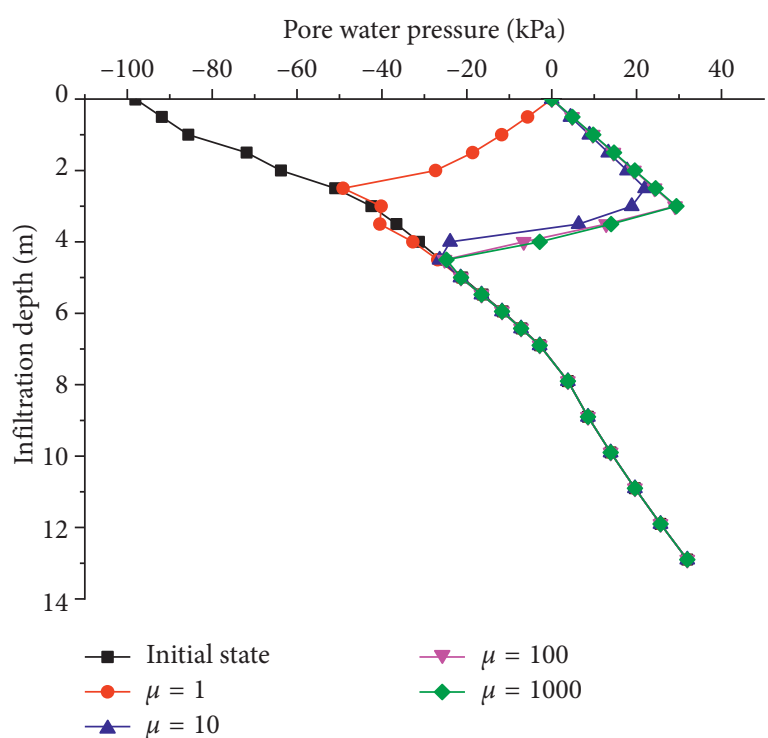

FIGURE 7: Distribution curves of pore water pressure with depth in different fracture permeability coefficient ratios $(x=15 \mathrm{~m})$.

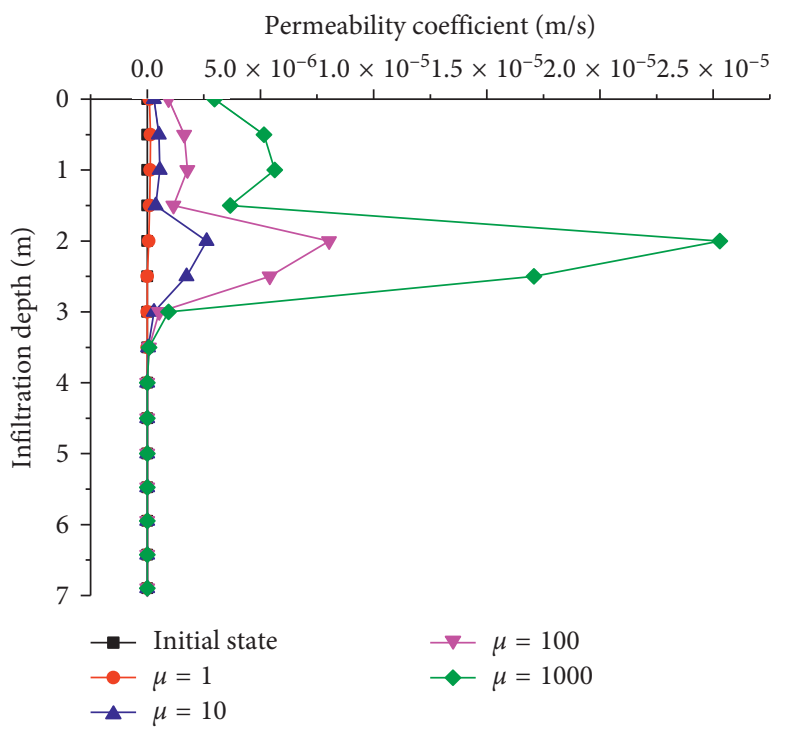

FIGURE 8: Distribution curve of the permeability coefficient with depth in different fracture permeability coefficient ratios $(x=15 \mathrm{~m})$.

process of rainfall is actually controlled by the soil permeability coefficient. However, when $\mu \geq 10$, the vertical permeability coefficient of fracture increases significantly relative to $\mu=1$. The fracture is saturated rapidly. The unsaturated permeability coefficient is changed to the saturation permeability coefficient. The permeation coefficient is much larger than the rainfall intensity, and the infiltration process of rainwater is controlled by the rainfall intensity. Therefore, when $\mu \geq 10$, the distribution of pore water pressure is basically the same, and the numerical difference is small.

Figure 9 shows a cloud map of pore water pressure in the fracture area with different permeability coefficient ratios. For convenience of analysis, only the fracture area is displayed. It can be seen that when $\mu=1$, the whole fracture area 


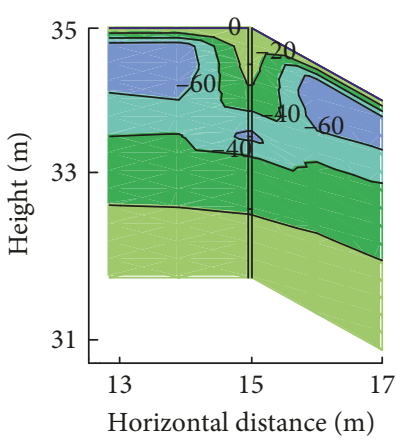

(a)

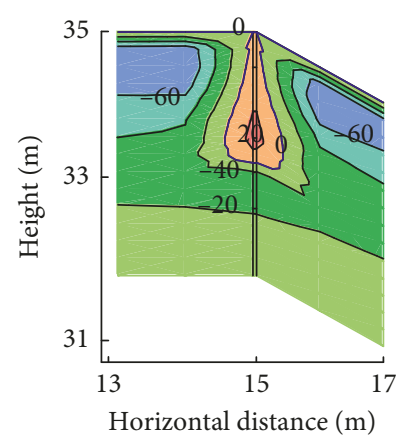

(b)

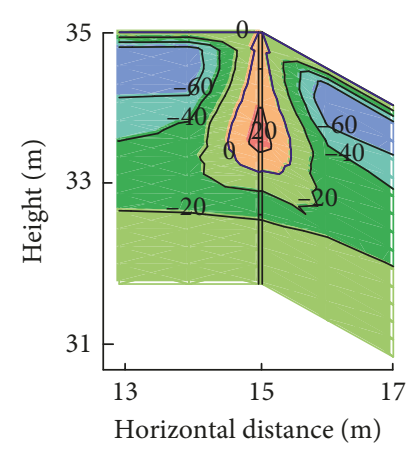

(c)

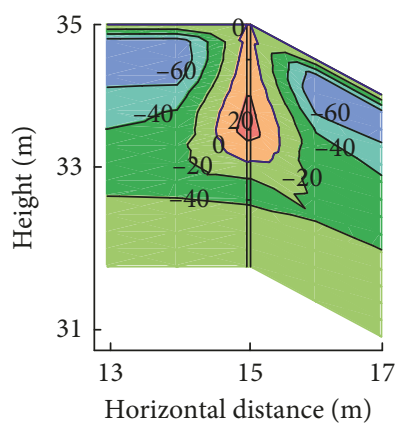

(d)

FiguRE 9: Pore water pressure cloud images of the fracture zone with different permeability coefficient ratios (fracture depth $3 \mathrm{~m}$, unit: $\mathrm{kPa}$ ): (a) $\mu=1$; (b) $\mu=10$; (c) $\mu=100$; (d) $\mu=1000$.

is the negative pressure area after 7 days of rainfall. When $\mu \geq 10$, a certain range of the saturation zone appears along the fracture. The maximum pore water pressure in this area is above $20 \mathrm{kPa}$. The distribution of the saturated area is similar, which further shows that the distribution of pore water pressure in Figure 7 is objective.

In conclusion, the influence of the fracture permeability coefficient on the rainfall infiltration process is mainly related to the relative magnitudes of the permeability coefficient and rainfall intensity. When the permeability coefficient of the fracture is less than the rainfall intensity, the permeability coefficient ratio has little effect on the infiltration process. When the permeability coefficient is greater than the rainfall intensity, the permeability coefficient ratio has a great influence on the infiltration process of rainwater. However, with the increasing of the permeability coefficient ratio, the influence of rainwater on the seepage process is not obvious.

\subsection{Influence of Anisotropic Direction of Fracture on the} Rainwater Infiltration Process. Figure 10 shows the variation of pore water pressure along the fracture section with buried depth at different fracture angles after rainfall. The following can be seen from the graph: (1) the pore water pressure caused by rainfall in the range of fracture depth changes from the negative value of the initial state to the positive value. The value increases linearly with the increase of buried depth. The difference of the pore water pressure distribution curve with different fracture angles is small. The pore water pressure distribution curve is parallel to that of the initial state. The results show that different fracture angles have little effect on distribution of pore water pressure. (2) The smaller the fracture angle is, the greater the maximum pore water pressure in the fracture depth range is, and the greater the depth of the positive pore water pressure is. Figure 11 shows the distribution of pore water pressure in the top of the slope at different fracture angles. It can be seen that, with the increase of fracture angle, the depth of infiltration decreases, but the range of the surface saturation area of slope increases obviously. The results show that the influence of fracture angle on the infiltration process of rainwater is mainly reflected on infiltration depth and the range of the surface saturation area.

From the above analysis, it can be seen that the influence of different fracture angles on the seepage field of the slope is mainly reflected in the infiltration depth, influence range, and degree. When the fracture angle is small, the influence depth of rainwater infiltration is greater, but it has little influence on the surface seepage field of the slope. However, when the fracture angle is large, the influence depth of rainwater infiltration is relatively small, but the influence on the surface seepage field of the slope is greater.

The reasons for this can be summarized as follows: (1) after a long period of rainfall, the fractures gradually reached saturation. The saturation permeability coefficient is much larger than the rainfall intensity, and the infiltration process is controlled by the rainfall intensity. Under the same condition of rainfall, almost all of rainwater is infiltrated. Therefore, the fracture angles have little effect on the distribution of pore water pressure with buried depth. (2) The smaller the fracture angle is, the greater the vertical permeability coefficient is. As a result, rainwater is more likely to cause saturation in the deep fracture areas. Accordingly, the surface saturation area of slope is relatively small. When the fracture angle increases, the vertical permeability coefficient becomes smaller and the horizontal permeability coefficient becomes larger. The rainwater is easy to gather in the shallow layer of the slope and seepage along the horizontal direction, which causes the saturation region of the slope surface to increase obviously.

\subsection{Influence of Fracture Density on the Rainwater Infiltration} Process. The size of fracture density often determines the stability of the slope. Especially, when the fracture depth is large, rainwater easily enters the deep slope directly, which has great influence on slope stability. Hence, in the middle to the top of the model, a different number of fractures whose length is $5 \mathrm{~m}$ are set up. In each of the five schemes, there are $1,2,3,4$, and 5 fissures, respectively. The five schemes are used to analyze the influence of fracture density on the rainwater infiltration process. Figure 12 shows the distribution of pore water pressure at different number of fractures. It can 


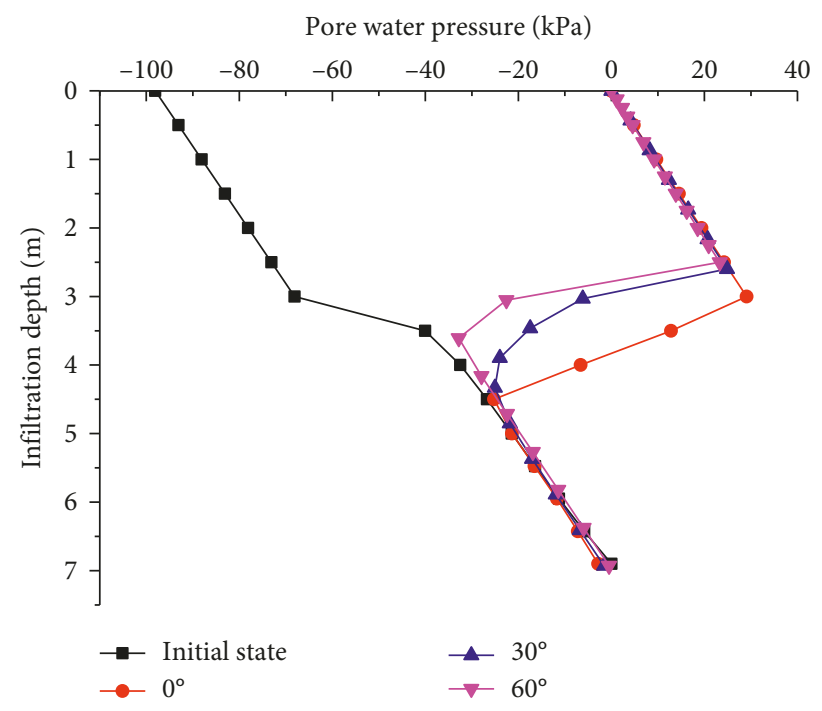

FIGURE 10: Distribution curves of pore water pressure with depth in different fracture angles (fracture depth $3 \mathrm{~m}$ ).

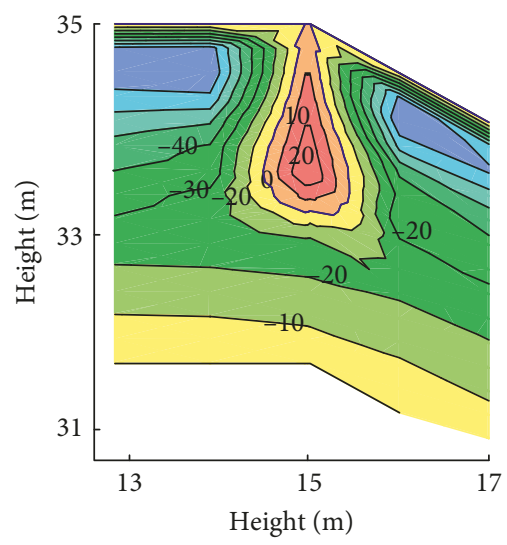

(a)

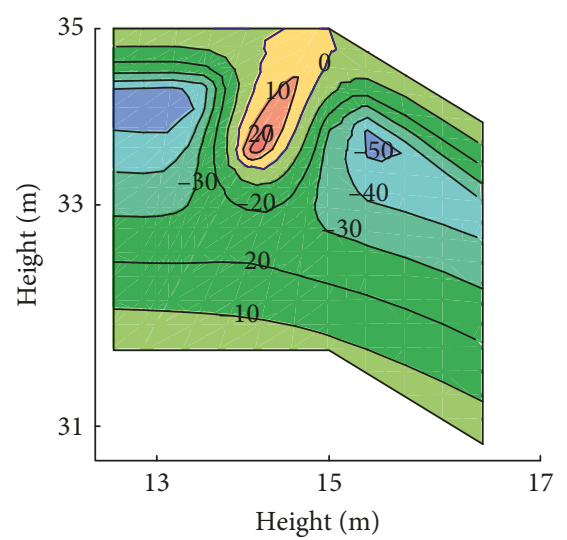

(b)

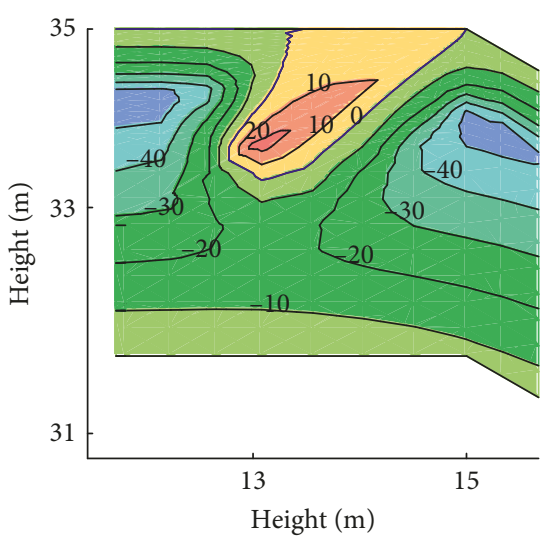

(c)

FIgURE 11: Pore water pressure in the fracture zone with different fracture angles (fracture depth $3 \mathrm{~m}$, unit: $\mathrm{kPa}$ ): (a) $\theta=0^{\circ}$; (b) $\theta=30^{\circ}$; (c) $\theta=60^{\circ}$.

be seen from Figure 12 that when there is no fracture, the slope still maintains the negative pressure state after rainfall, and there is no saturation zone. When there is a fracture, rainwater infiltrates along the fracture and forms a saturated positive pressure zone inside the slope. With the increase of fracture density, the saturated positive pressure region is connected to each other in the slope. The influence range and the degree of the rainwater on the seepage field are larger and larger. The range of the saturated zone formed by 1 to 5 fractures is $16.4 \mathrm{~m}^{2}, 34.7 \mathrm{~m}^{2}, 60.9 \mathrm{~m}^{2}, 75.6 \mathrm{~m}^{2}$, and $110.7 \mathrm{~m}^{2}$, respectively. The area of the saturated area increases with the number of fractures in the form of the formula $y=15.968 x^{1.2073}$, as shown in Figure 13. Figure 14 shows the variation process of the saturation line in the fracture with rainfall time when $5 \mathrm{~m}$ long fissures are distributed in the middle and upper parts of the slope. The saturation zone formed by each fracture exists independently during 2 days of rainfall. After 3 days of rainfall, the saturated area of the lower part of the single fracture began to merge and connect gradually. The saturation line increases obviously with the continuous rainfall.

In conclusion, the existence of long fractures as the dominant seepage path will help rainwater enter the slope quickly. Rainfall can directly recharge the slope groundwater and form a large area of the saturation area. The existence of the saturated zone increases the weight of soil and reduces the unsaturated strength of soil. Especially when there are many fractures in the slope at the same time, the influence area of rainwater infiltration will be further enlarged, which will be unfavorable to the slope stability.

4.4. Analysis of Influence of Fracture on Slope Stability. The formation of cracks in soil slopes, especially loose slopes, mainly comes from two aspects: (1) slip of slope soil; (2) when the upper soil evaporates and shrinks, the lower soil cannot synchronize, so the upper and lower soil shrinkage is 


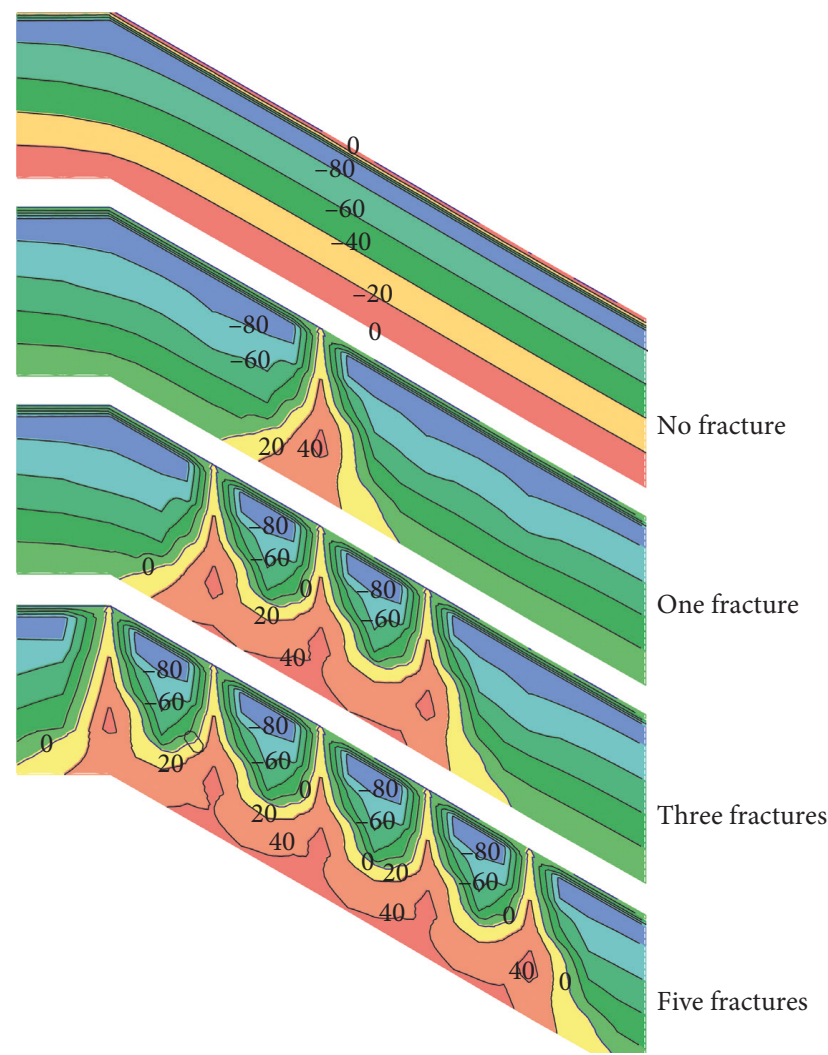

FIGURE 12: Effect of fracture quantity on pore water pressure field (fracture depth $3 \mathrm{~m}$, unit: $\mathrm{kPa}$ ).

uneven, resulting in cracks. The existence of a fracture causes it to lose its original strength on the surface of a fracture [27]. When the crack develops to a certain extent, it will inevitably affect the slope stability [28]. Specifically, the most important causes of soil slope instability caused by fractures can be summarized in three aspects: (1) as far as the fracture itself is concerned, the degree of development of the fracture will determine the strength of the soil, which includes the density, depth, and width of the fracture. At present, there is not a criterion of how the degree of crack development affects the strength of soil, but some useful research has been carried out [29]. (2) The pore water pressure and water content increase due to rainwater entering the fractures and slope soil. The unsaturated strength of the soil will be reduced. At the same time, the gravity of the soil will be increased, which will lead to the increase of the sliding force. (3) For colluvial soil slope, the lower part of the slope is impervious bedrock. When rainwater enters the fracture and surrounding soil, the hydrodynamic pressure will be generated in the sliding body of the upper part of the bedrock, and the slope sliding moment will be significantly increased.

In view of the fact that fracture affects slope stability, the influences of the fracture depth, fracture angle, and fracture density on the rainwater infiltration process are analyzed. The results show that the pore water pressure of the soil around the fracture increases under the condition of rainfall. The soil reaches the saturation state (water content increases). When the fracture density is high, the continuous saturation zone is

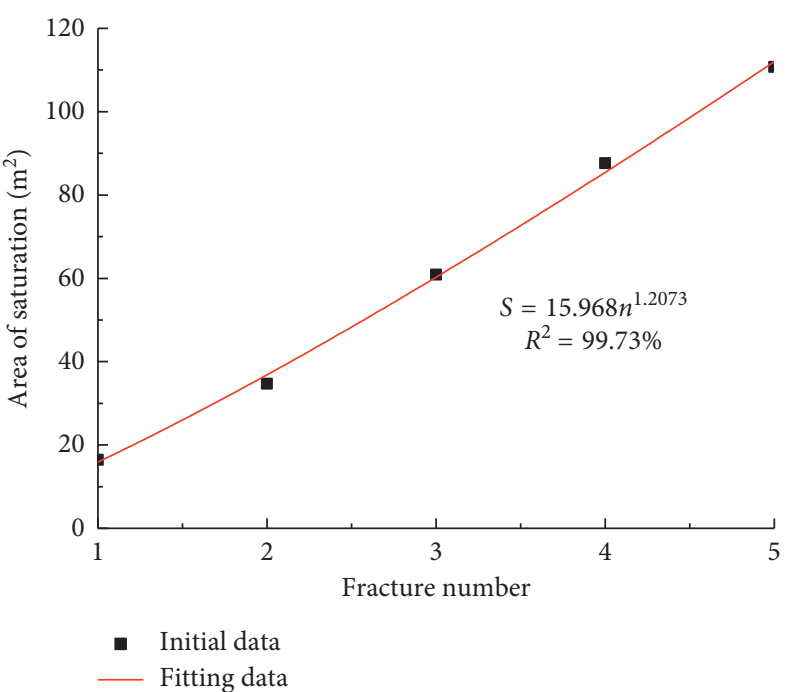

FIGURE 13: The relationship between the fracture numbers and the area of saturation.

formed inside the slope. According to bivariate unsaturated shear strength formula put forward by Fredlund et al. [30], the strength of unsaturated soil is determined by several factors $[31,32]$ such as effective shear strength parameters $\left(c^{\prime}\right.$ and $\left.\varphi^{\prime}\right)$, matrix suction $\left(u_{\mathrm{a}}-u_{\mathrm{w}}\right)$, and $\varphi_{\mathrm{b}}$. When the soil is saturated, the effective shear strength parameters $\left(c^{\prime}\right.$ and $\left.\varphi^{\prime}\right)$ decrease, the matrix suction almost disappears in the saturated region, and $\varphi_{\mathrm{b}}$ decreases accordingly. As a result, the strength of unsaturated soil decreases significantly. Moreover, when rainwater enters the soil along the fractures, the weight of soil will increase, which leads to the increase of slope sliding force. Combining the calculation results with the theory of unsaturated shear strength shows that fracture can enhance the infiltration of rainwater in the slope soil and thus affects the slope stability significantly. The range of the saturated zone and variation law of the pore water pressure under fracture seepage are obtained, which provides a reference for the parameter partition assignment of slope stability analysis under fracture seepage.

\section{Conclusions}

The influence of anisotropy of slope fracture on the rainwater infiltration process of slope soil is simulated by the numerical method, and the following conclusions are obtained:

(1) The fracture depth, permeability coefficient ratio, fracture angle, and fracture density all affect the infiltration of rainwater to a certain extent and mainly reflect in the influence on pore water pressure, infiltration rate of rainwater, infiltration depth, and infiltration range. It is worth considering in slope stability analysis and slope drainage design.

(2) Under the same rainfall conditions, the greater the fracture depth, the greater the pore water pressure in the fissure, and the greater the influence range on the slope. The effect of the permeability coefficient ratio 


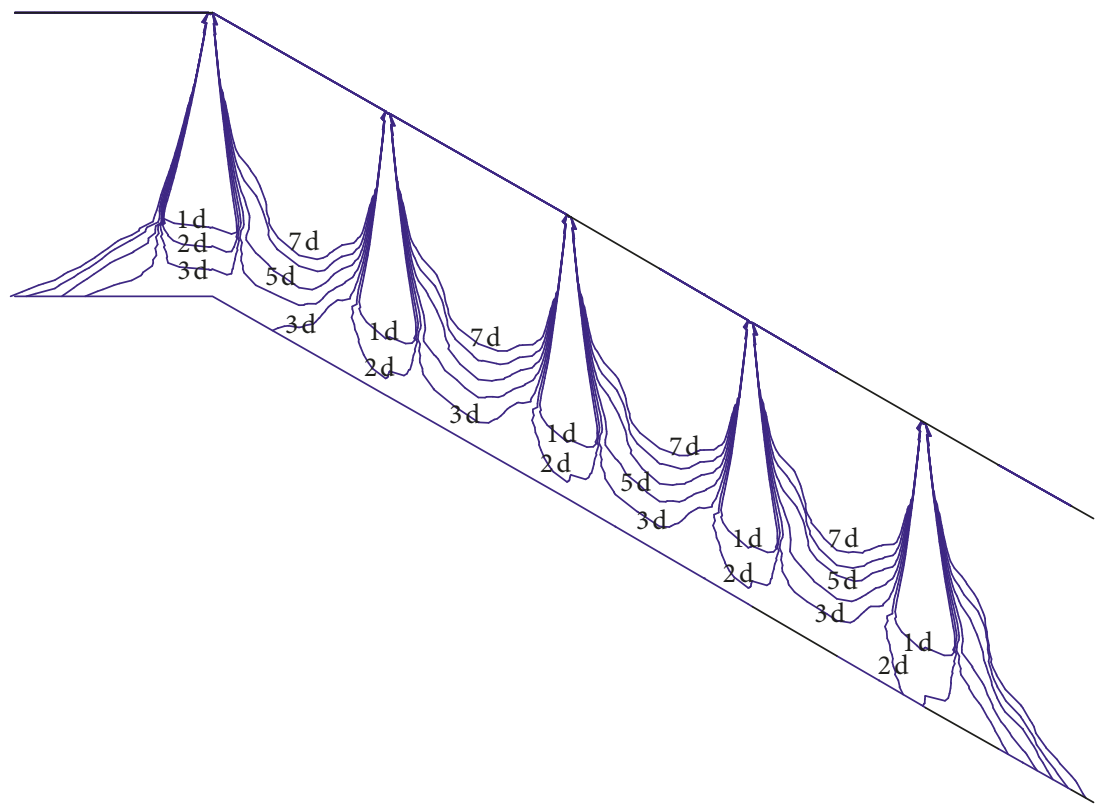

FIgURE 14: The distribution of the phreatic line with the rainfall time when the fracture density is 5 (fracture depth $3 \mathrm{~m}$ ).

on the infiltration process of rainwater is mainly related to the relative size of the permeability coefficient and rainfall intensity. When the permeability coefficient is less than the rainfall intensity, the influence of $\mu$ on the infiltration process of rainwater is small. While the permeability coefficient is greater than the rainfall intensity, the influence of $\mu$ on the infiltration process of rainwater becomes more and more significant.

(3) Fracture angle has little effect on the distribution law of pore water pressure. The influence of rainwater on the surface layer of slope is big when the angle is large. For small fracture angle, rainwater has a greater infiltration depth.

(4) Under the same rainfall condition, the area of the saturated zone increases exponentially with the number of fractures. The concentrated distribution of long fractures is the direct cause of the large-scale connected saturated zone in the slope and the rise of the groundwater level.

\section{Data Availability}

The data used to support the findings of this study are available from the corresponding author upon request.

\section{Conflicts of Interest}

The authors declare that there are no conflicts of interest regarding the publication of this paper.

\section{Acknowledgments}

The authors gratefully acknowledge the National Key Research and Development Program of China (2017YFC0805307), National Natural Science Foundation of China (51878078,
51838001, 51878070, 51508040, and 51678074), Excellent Youth Foundation of Natural Science Foundation of Hunan Province (2018JJ1026), Jiangsu Provincial Natural Science Fund Projects (BK20150885), and Open Fund of Engineering Laboratory of Spatial Information Technology of Highway Geological Disaster Early Warning in Hunan Province (Changsha University of Science and Technology), China (KFJ160601).

\section{References}

[1] L. T. Zhan, H. Li, Y. M. Chen, and D. G. Fredlund, "Parametric analyses of intensity-duration curve for predicting rainfall-induced landslides in residual soil slope in southeastern coastal areas of China," Rock and Soil Mechanics, vol. 33, no. 3, pp. 872-880, 2012, in Chinese.

[2] R. I. Borja and J. A. White, "Continuum deformation and stability analyses of a steep hillside slope under rainfall infiltration," Acta Geotechnica, vol. 5, no. 1, pp. 1-14, 2010.

[3] Y. Ju, Q. G. Zhang, Y. M. Yang, H. P. Xie, F. Gao, and H. J. Wang, "An experimental investigation on the mechanism of fluid flow through single rough fracture of rock," Science China Technological Sciences, vol. 56, no. 8, pp. 2070-2080, 2013.

[4] J. Qian, Z. Chen, H. Zhan, and H. Guan, "Experimental study of the effect of roughness and Reynolds number on fluid flow in rough-walled single fractures: a check of local cubic law," Hydrological Processes, vol. 25, no. 4, pp. 614-622, 2011.

[5] S. Chen, F. Liu, and K. Burrage, "Numerical simulation of a new two-dimensional variable-order fractional percolation equation in non-homogeneous porous media," Computers \& Mathematics with Applications, vol. 68, no. 12, pp. 2133-2141, 2014.

[6] S. B. Huang, Q. S. Liu, A. P. Cheng, and Y. Z. Liu, "A coupled hydro-thermal model of fractured rock mass under low temperature and its numerical analysis," Rock and Soil Mechanics, vol. 39, no. 2, pp. 735-744, 2018. 
[7] T. H. Yang, P. Jia, W. H. Shi, P. T. Wang, H. L. Liu, and Q. L. Yu, "Seepage-stress coupled analysis on anisotropic characteristics of the fractured rock mass around roadway," Tunnelling and Underground Space Technology Incorporating Trenchless Technology Research, vol. 43, pp. 11-19, 2014.

[8] J. R. Chai and W. S. Xu, "Coupling analysis of unsteady seepage and stress fields in discrete fractures network of rock mass in dam foundation," Science China Technological Sciences, vol. 54, no. 1, pp. 133-139, 2011.

[9] B. Y. Su, W. J. Zhang, J. C. Sheng, X. C. Xu, M. L. Zhan, and J. S. Liu, "Study of permeability in single fracture under effects of coupled fluid flow and chemical dissolution," Rock and Soil Mechanics, vol. 31, no. 11, pp. 3361-3366, 2010, in Chinese.

[10] L. Zeng, H. B. Bian, Z. N. Shi, and Z. M. He, "Forming condition of transient saturated zone and its distribution in residual slope under rainfall conditions," Journal of Central South University, vol. 24, no. 8, pp. 1866-1880, 2017.

[11] Q. S. Liu, Y. X. Wu, and B. Liu, "Discrete element analysis of effect of stress on equivalent permeability of fractured rockmass," Chinese Journal of Rock Mechanics and Engineering, vol. 30, no. 1, pp. 176-183, 2011, in Chinese.

[12] B. G. Chen and E. X. Song, "A numerical method for discrete fracture network model for flow and heat transfer in twodimensional fractured rocks," Chinese Journal of Rock Mechanics and Engineering, vol. 33, no. 1, pp. 43-51, 2014, in Chinese.

[13] C. T. O. Leung and R. W. Zimmerman, "Estimating the hydraulic conductivity of two-dimensional fracture networks using network geometric properties," Transport in Porous Media, vol. 93, no. 3, pp. 777-797, 2012.

[14] L. L. Xue and S. H. Chen, "Composite element model of seepage-normal stress coupling for rock fractures," Chinese Journal of Rock Mechanics and Engineering, vol. 26, no. 1, pp. 2613-2619, 2007, in Chinese.

[15] S. H. Chen, H. R. Wang, and W. L. Xiong, "Study of the seepage characteristics of joint surface," Journal of Wuhan University of Hydraulic and Electric Engineering, vol. 22, no. 1, pp. 53-60, 1989, in Chinese.

[16] J. X. Huo, H. Z. Song, J. N. Du, and Q. C. Guan, "Coupled fluid flow and chemical dissolution model based on surface reaction and mass transfer control in a rough fracture," Chinese Journal of Rock Mechanics and Engineering, vol. 34, no. 5, pp. 1013-1021, 2015, in Chinese.

[17] F. Q. Song, X. Hu, K. Ji, and X. Huang, "Effect of fluid-solid coupling on shale mechanics and seepage laws," Natural Gas Industry B, vol. 5, no. 1, pp. 41-47, 2018.

[18] Y. Zeng, X. D. Kang, X. Q. Xie, E. Tang, and C. Liu, "Studies on seepage law considering stratigraphic dips," Petroleum, vol. 3, no. 4, pp. 470-475, 2017.

[19] S. Ou, L. Wang, P. Wang, Z. Wang, J. Huang, and D. L. Zhou, "Numerical analysis of seepage flow characteristic of collapse column under the influence of mining," International Journal of Mining Science and Technology, vol. 23, no. 2, pp. 237-244, 2013.

[20] Z. Wang, J. Pan, Q. Hou, B. Yu, M. Li, and Q. H. Niu, "Anisotropic characteristics of low-rank coal fractures in the Fukang mining area, China," Fuel, vol. 211, pp. 182-193, 2018.

[21] S. Liu, W. Li, Q. Wang, Z. Wu, and Z. Yang, "Numerical simulation on crack propagation of rock mass with a single crack under seepage water pressure," Advances in Mechanical Engineering, vol. 9, no. 10, article 168781401773289, 2017.

[22] Z. Y. Ye, Q. H. Jiang, C. B. Zhou, and Y. Z Liu, "Numerical analysis of unsaturated seepage flow in two-dimensional fracture networks," International Journal of Geomechanics, vol. 17, no. 5, article 04016118, 2016.

[23] Z. M. Jiang, J. Tang, G. Xie, and W. J. Chen, "Water pressure test of rock permeability of the slope in Ruchen expressway," Highway \& Auto-Motive Application, vol. 11, no. 6, pp. 101104, 2010, in Chinese.

[24] X. Wu, Y. Wei, J. Wang, J. Xia, C. Cai, and Z. Wei, “Effects of soil type and rainfall intensity on sheet erosion processes and sediment characteristics along the climatic gradient in centralsouth China," Science of the Total Environment, vol. 621, pp. 54-66, 2018.

[25] J. P. Yuan, Y. L. Lin, P. Ding, and C. L. Han, "Influence of anisotropy induced by fissures on rainfall infiltration of slopes," Chinese Journal of Geotechnical Engineering, vol. 38, no. 1, pp. 76-82, 2016, in Chinese.

[26] L. Scholtès and F. V. Donzé, "Modelling progressive failure in fractured rock masses using a 3D discrete element method," International Journal of Rock Mechanics and Mining Sciences, vol. 52, pp. 18-30, 2012.

[27] J. H. Zhang, J. Li, Y. S. Yao, J. L. Zheng, and F. Gu, "Geometric anisotropy modeling and shear behavior evaluation of graded crushed rocks," Construction and Building Materials, vol. 183, pp. 346-355, 2018.

[28] L. J. Munkholm, R. J. Heck, B. Deen, and T. Zidar, "Relationship between soil aggregate strength, shape and porosity for soils under different long-term management," Geoderma, vol. 268, pp. 52-59, 2016.

[29] Z. Z. Yin, J. P. Yuan, and J. Wei, "Influences of fissures on slope stability of expansive soil," Chinese Journal of Geotechnical Engineering, vol. 34, no. 12, pp. 2155-2161, 2012, in Chinese.

[30] D. G. Fredlund, N. R. Morgenstern, and R. A. Widger, "The shear strength of unsaturated soils," Canadian Geotechnical Journal, vol. 15, no. 3, pp. 313-321, 2002.

[31] J. H. Zhang, J. H. Peng, J. L. Zheng, and Y. S. Yao, "Characterisation of stress and moisture-dependent resilient behaviour for compacted clays in South China," Road Materials and Pavement Design, pp. 1-14, 2018.

[32] J. H. Zhang, J. H. Peng, J. Li, and J. L. Zheng, "Variation of resilient modulus with soil suction for cohesive soils in South China," International Journal of Civil Engineering, pp. 1-13, 2018. 


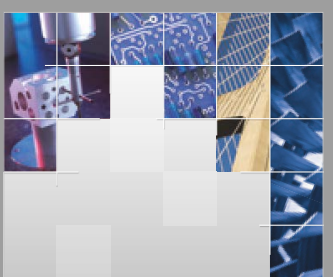

\section{Enfincering}
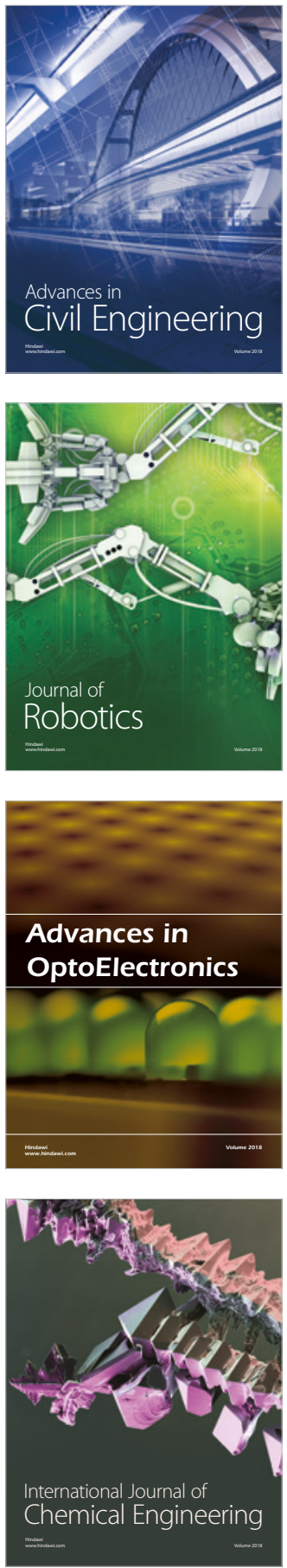

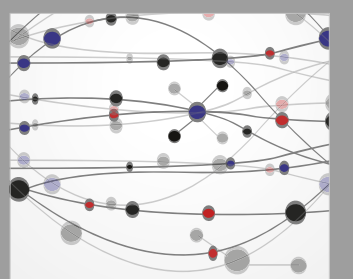

\section{Rotating \\ Machinery}

The Scientific World Journal

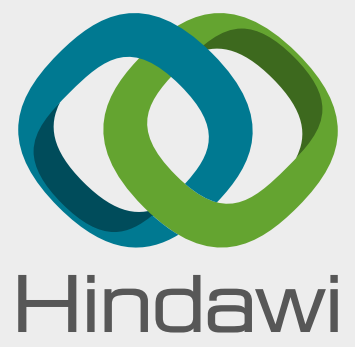

Submit your manuscripts at

www.hindawi.com
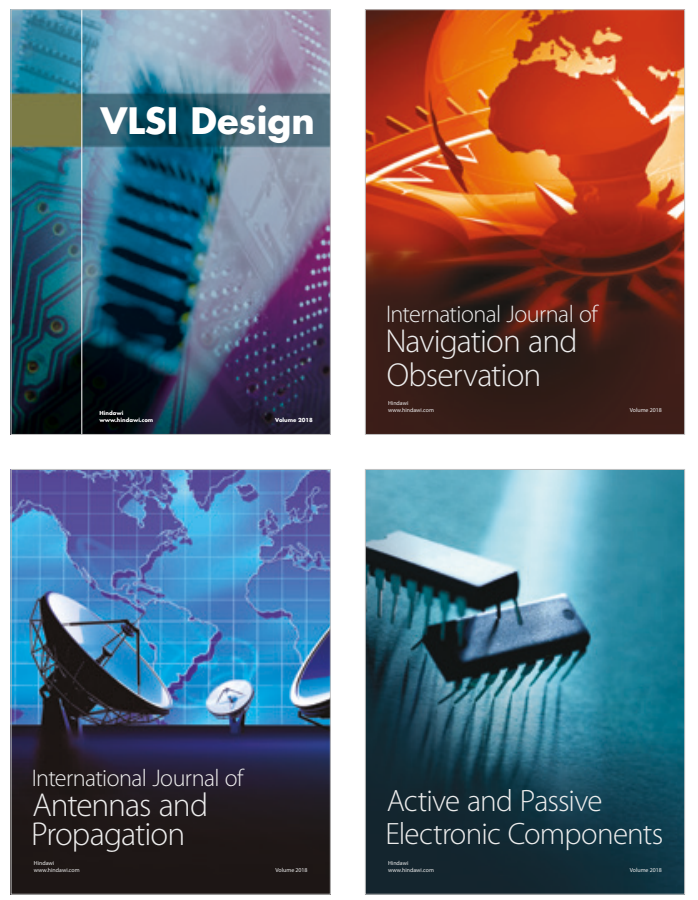
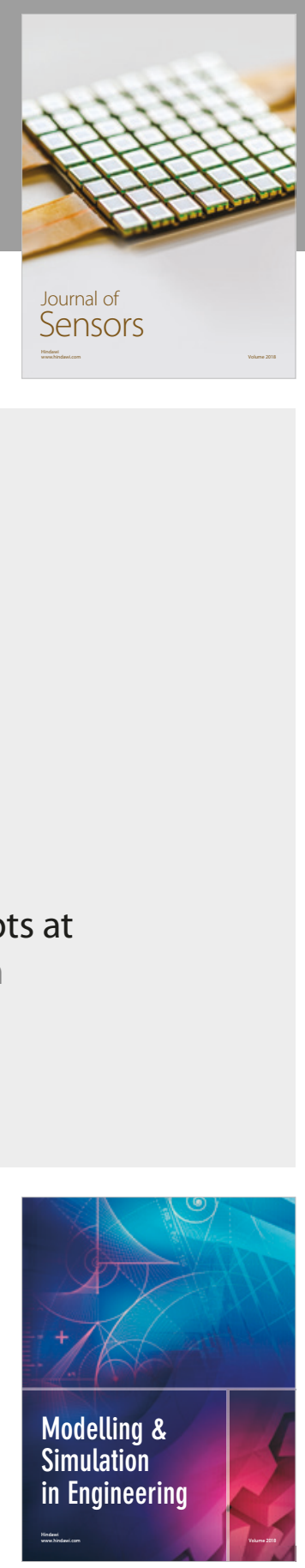

\section{Advances \\ Multimedia}
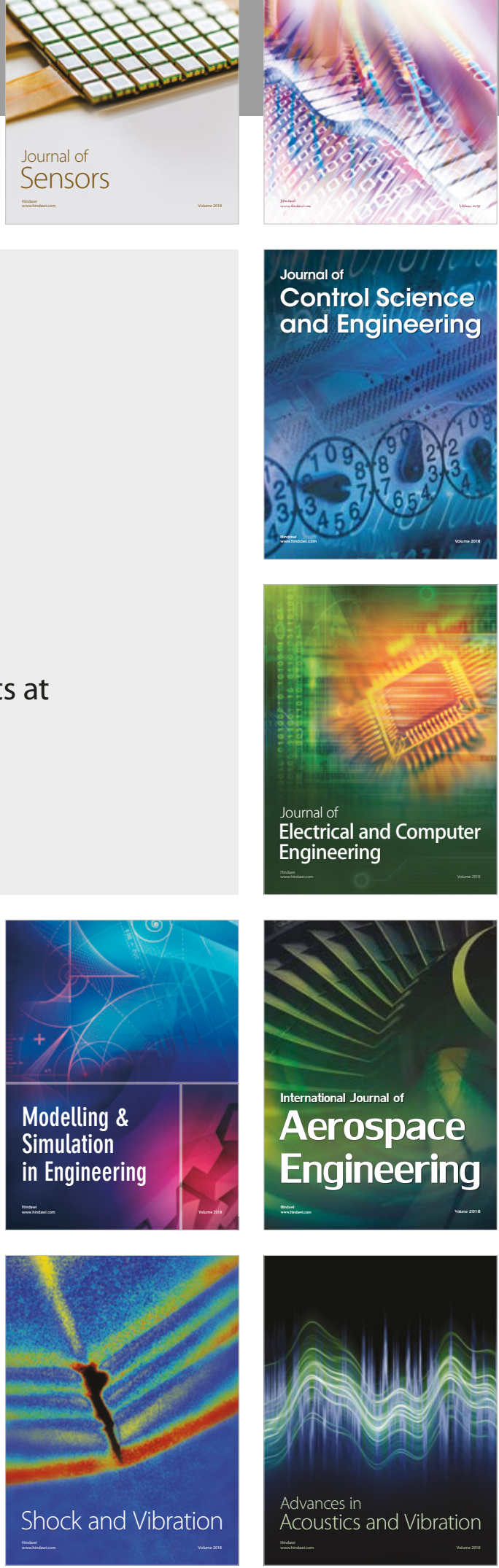